\title{
Prevalence and outcome of rotaviral diarrhoea among children under five years- a single centre study
}

\author{
Sunil $\mathbf{P}^{1}$, Thanda $\mathbf{P}^{2}$, Mali $\mathbf{D}^{3}$, Reddy $\mathbf{R}^{4}$ \\ ${ }^{1}$ Dr. Pawar Sunil, Consultant Neonatologist, Durgabai Deshmukh Hospital and Research Centre, Hyderabad, India, \\ Thumbay Hospital Group, Department of Paediatrics, Hyderabad, India, ${ }^{2}$ Dr. Prasad Thanda, Consultant Pediatrician, \\ Krishna Institute of Medical Sciences, Department of Paediatrics, Secunderabad, India, ${ }^{3}$ Dr. Dada Mali, Consultant \\ Pediatrician, Krishna Institute of Medical Sciences, Department of Paediatrics, Secunderabad, India. ${ }^{4}$ Dr. Rajshekhar \\ Reddy, Consultant Pediatrician, Thumbay Hospital Group, Department of Paediatrics, Hyderabad, India.
}

Corresponding author: Dr. Pawar Sunil, Durgabai Deshmukh Hospital and Research Centre, Vidya Nagar, Osmania University Road Medical Campus, Hyderabad, India. Tel.: +919000711682, E-mail- drsunilpawar1@gmail.com

\begin{abstract}
Introduction: Diarrhoea refers to the passage of loose or watery stools or an increased frequency of stools for the child and occurs at some point in the life of nearly every child. Diarrhoea is not a disease, but is a symptom of a number of illnesses. Diarrhoea is common and rarely serious. It can lead to dehydration, which alters the child's natural balance of water, and to electrolyte (sodium, potassium, chloride) imbalance. It can be serious if not treated promptly. Material \& method: This prospective observational cohort study done 3 different hospitals in Hyderabad. The stool samples were collected and immunochromatographic test done to detect the rotavirus and ELISA done to detect the strain. Results: The 108 patients were tested for rotavirus antigen. The highest incidence $(38.6 \%)$ of rota viral diarrhoea is seen in children in age group of $0-12$ months. Fifty-five (50.93\%) patients were positive for the immunochromatographic test. Rotavirus infections were most common during the months from December to March. The male predominance was obtained in incidence of rota viral diarrhoea during this study. In only $17.3 \%$ cases with acute diarrhoea had severe dehydration requiring admission and intra-venous fluid therapy. The most common strain was G1P. All patients immunized with rotavirus vaccine are protected from rotaviral diarrhoea. Conclusion: Study revealed maximum prevalence of rota viral diarrhoea in month from December to March. All vaccinated children with rota virus vaccine were protected from rota viral infection.
\end{abstract}

Key words: Diarrhoea, rotavirus, infants, children, outcomes

\section{Introduction}

Diarrhoea is one of the major cause for mortality in under five children in India resulting in an estimated 24 million outpatients visits, 2.5 million hospitalizations and 450,000 deaths among children below 5 years of age worldwide $[1,2]$. The under five mortality rate was 11.1 per 1000 live birth in 2005 [2].

India has made steady progress in reducing deaths in children younger than 5 years, with total deaths declining from 2.5 million in 2001 to 1.5 million in $2012[3,4]$. Few studies has been done in India to find out the cause of diarrhoea, and most of them were hospital based studies. Most of the studies conducted in

Manuscript received: $14^{\text {th }}$ January 2017

Reviewed: $20^{\text {th }}$ January 2017

Author Corrected: $27^{\text {th }}$ January 2017

Accepted for Publication: $4^{\text {th }}$ February 2017 our country shows that approximately $40 \%$ of cases of diarrhoea among hospitalized children are due to rotavirus infection $[5,6]$.

There are limited studies showing data on rotavirus in Telangana state. There is a need for additional research and public health surveillance to ensure that adequate information about rotavirus is obtained from diverse populations in India.

The present study was performed to estimate the proportion of diarrhea due to rotavirus and to identify the rotavirus strains among diarrheal children less than 5 years from KIMS Hyderabad, India. The study results can guide public authorities to make a plan for universal coverage of children with vaccination. 


\section{Methods}

This study was conducted at KIMS Hospital, Hyderabad, India. This hospital is a tertiary care center having one of the biggest referral centres in Hyderabad. The study was approved by Institutional research board (IRB) of KIMS Hospital. The study duration was from April 2009 to March 2011.

The objectives of the study were to determine incidence of rotavirus in acute gastroenteritis and its outcome in children less than 5 years of age coming to K.I.M.S hospital Hyderabad, India and also to look at the incidence of the same among vaccinated children. The inclusion criteria were the children suffering from acute gastroenteritis in the age group of less than 5 years, who attended outpatient department. The informed consent was obtained from the parent or guardian.

Those children admitted with acute diarrhoea their parents were interviewed for duration, fever, vomiting and any other signs of dehydration. The severity of dehydration was assessed according to the WHO Integrated Management of Childhood Illness Model
Handbook guidelines and was categorized into severe, some or no dehydration [7]. The standard proforma based on WHO protocol was prepared and used to collect all details and data [8].

\section{Specimen preparation and analysis:}

The samples were collected from the admitted patients in two bottles and stored at $4^{\circ} \mathrm{C}$. On the first sample the VIKIA rota test done and the second sample sent to the National Institute of Virology, Hyderabad for performing ELISA. Rotavirus positive samples were analysed by reverse transcription polymerase chain reaction for $\mathrm{G}$ and $\mathrm{P}$ typing at National Institute of Virology Hyderabad. For performing the VIKIA rota test the sample was allowed to come to room temperature $\left(15-30^{\circ} \mathrm{C}\right)$. The "Rota" test device is a rapid test, based on the immunochromatographic technique (ICT), for the detection of rotaviruses in a stool extract. Rapid diagnosis of the infectious agent enables inadequate antibiotic treatment to be avoided and the infected patient to be rapidly isolated.

\section{Results}

Hundred and eight children were participated in the study, among this 60 were treated on outpatient basis. And 48 were treated on indoor patient basis. Fifty-five cases (49\%) showed positivity for rotavirus antigen. The mean (SD) age of children was 15.9 (12.8) months; male 15.2 (12.7) vs. female 16.8 (12.9). In the rotavirus positive group, the age between o to 12 month showed higher score when compared to other age groups of 13 to 24 months.

Overall male predominance was observed in both rotaviruses positive and rotavirus negative groups. The most common age was below 2 years. In $57.3 \%$ of rotavirus positive and $61.8 \%$ cases of rotavirus negative patients, there were no signs of dehydration. Some signs of dehydration were observed in $25.4 \%$ of rotavirus positive and $18.4 \%$ of rotavirus negative group. In less than one fifth cases in both groups, dehydration was severe requiring hospitalization and IV fluid therapy. So far dehydration status was concerned; there was no statistically significant difference in the grade of dehydration between two groups. The mean duration of hospital stay of admitted patients was 4.5 days. It also showed no significant difference between the two groups. Almost all cases (97\%) of rotavirus positive diarrhoea recovered uneventfully without any complication, only one case developed complication in from of seizure.

Tables 1: Age Distribution of case.

\begin{tabular}{|c|c|c|c|c|}
\hline Age Group & 0-6 Months & $\mathbf{7 - 1 2}$ Months & 13-24 months & 25-60 Months \\
\hline No. of cases & 20 & 31 & 38 & 19 \\
\hline
\end{tabular}

Table 2: Distribution of cases according to department of enrolment.

\begin{tabular}{|c|c|c|c|}
\hline $\begin{array}{c}\text { Department of Paediatrics } \\
\text { KIMS hospital Hyderabad }\end{array}$ & Rotavirus Positive & Rotavirus Negative & Total \\
\hline O.P.D & $35(64.1 \%)$ & $32(61 \%)$ & $67(62 \%)$ \\
\hline I.P.D. & $20(35.9 \%)$ & $21(39 \%)$ & $41(38 \%)$ \\
\hline Total & $55(100 \%)$ & $53(100 \%)$ & $108(100 \%)$ \\
\hline
\end{tabular}


Table 3: Treatment outcome of hospitalized patients (Fisher's exact test $=\mathbf{0 . 2 0 3}, \mathrm{p}(\mathrm{value}=\mathbf{1})$.

\begin{tabular}{|c|c|c|c|}
\hline Outcome & Rotavirus Positive & Rotavirus negative & Total \\
\hline Improved \& discharged & $19(97 \%)$ & $19(92.3 \%)$ & $(44)(91.69 \%)$ \\
\hline Developed complications & $1(3 \%)$ & $2(6.47 \%)$ & $3(6.25 \%)$ \\
\hline Total & $20(100 \%)$ & $21(100 \%)$ & $48(100 \%)$ \\
\hline
\end{tabular}

TABLE 4: Comparison of grade of dehydration between 2 groups (chi-squares-test $X v=0.698, p$ value $=0.705$ ).

\begin{tabular}{|c|c|c|c|}
\hline Dehydration Status & Rotavirus Positive & Rotavirus Negative & Total Cases \\
\hline No dehydration & $32(57.3 \%)$ & $33(61.8 \%)$ & $65(60.19 \%)$ \\
\hline Same dehydration & $14(25.4 \%)$ & $10(18.4 \%)$ & $24(22.22 \%)$ \\
\hline Severe dehydration & $9(17.3 \%)$ & $10(19.8 \%)$ & $19(17.59 \%)$ \\
\hline Total & $55(100 \%)$ & $53(100 \%)$ & $108(100 \%)$ \\
\hline
\end{tabular}

\section{Discussion}

Rotavirus infections were detected in almost all months of the year and chances of coinfections are more in children [9]. Rotavirus is main cause of acute gastroenteritis in children [10]. Worldwide diarrhea related mortality has decreased mainly because of better therapeutic interventions along with provision of safe drinking water, improvement of sanitation and popularization of primary health care activities. Many studies done in different area have shown the inpatient role of rotavirus as a cause of diarrhea in children in both developed and developing countries. In this study we estimated the diarrheal disease burden due to rotavirus infection among children below 5 years old with diarrhea in Secunderabad. Our study showed a rotavirus prevalence of $50.93 \%$ in children with acute diarrhea attending, Krishna institute of medical sciences at Secunderabad. In this study $92 \%$ of rotavirus diarrhea, were identified in age group of less than 2 years.

This result is comparable to findings in other studies. In our study higher $(38.6 \%)$ prevalence was seen in children from 0-12 months of Age. The highest prevalence during second half of infancy can be explained by declining immunity incurred through breast feeding and starting "oral phage" of normal development of milestones in children when babies put almost everything into mouth. The male preponderance in rotavirus diarrhea obtained in my study. Cases for male predominance remain unclear. Majority of rotavirus diarrhea cases attended and treated on outdoor patient basis. This indicates that majority of rotaviral diarrhea were not clinically severe enough to be hospitalized. The statistical analysis of distribution of cases according of department of enrolment by using Chi-square test shows there is no any statistical difference among both groups, results are comparable ( $\mathrm{p}$ value $=0.727$ ), i.e. Rota viral positive cases can be managed on O.P. basis similar to other diarrhea cases. The statistical analysis of compartment of dehydration status by using Chi-square test, among two group shows there is no any statistical difference among both groups, results are comparable ( $\mathrm{p}$ value $=0.705$ ), i.e. there no difference in grade of dehydration between two groups.

The statistical analysis of outcome of hospitalized patients between two groups by using Fisher's exact test $(0.203)$ reveals there no difference among two groups ( $p$ value $=1$ ). In this study, significant association of nausea and vomiting with rotaviral diarrhea is also evident. In only $17.3 \%$ cases, dehydration was severe requiring hospitalization for intravenous fluid therapy. No death reported among ICT positive cases. Only one death was observed in ICT negative group. This unfortunately had severe malnutrition along with diarrhea Despite maximum efforts, and this case associated with malnutrition [11,12]. We failed to enroll all diarrhea patients attending hospital during study period. Maximum no of rotaviral diarrhea found in month from December to march. (Late winter) (34 cases out of 55 
cases). Cases vaccinated with rotavirus vaccines were found to be negative and protected from Rota viral infection

\section{Conclusion}

The study showed higher incidence of rota viral diarrhea among children presenting with acute diarrhea. The highest incidence of rota viral diarrhea is seen in children in age group of 0-12 months. The male predominance was obtained in incidence of rota viral diarrhea during this study. All vaccinated children with rota virus vaccine were protected from rota viral infection.

Funding: Nil, Conflict of interest: None initiated, Perission from IRB: Yes

\section{References}

1. TateJE, Burton AH, Boschi Pinto C, Steele AD, Duque J, ParasharUD. 2008 estimate of worldwide rotavirus associated mortality in children younger than 5 years before the introduction of universal rotavirus vaccination programmes: A systematic review and Meta -analysis. Lancet Infect Dis. 2012;12:13641.

2. Million Death Study Collaborators, Bassani DG, Kumar R, Awasthi S, Morris SK, Paul VK, et al. Causes of neonatal and child mortality in India : a nationally representative mortality survey. Lancet. $2010 ; 376: 185360$.

3. Bhan MK. Accelerated progress to reduce under-5 mortality in India. Lancet Glob Health. 2013 Oct;1(4):e172-3. doi: 10.1016/S2214-109X (13) 70076-

7. Epub 2013 Sep 19.

4. Kelkar SD, Purohit SG, Boralkar AN, Verma SP. Prevalence of rotavirus diarrhea among outpatients and hospitalized patients: a comparison. Southeast Asian J Trop Med Public Health. 2001 Sep;32(3):494-9.

5. Kahn G, Fitzwater S, Tate J, Kang G, Ganguly N, Nair G, Steele D, Arora R, Chawla-Sarkar M, Parashar U, Santosham M. Epidemiology and prospects for prevention of rotavirus disease in India. Indian Pediatr. 2012 Jun;49(6):467-74.

6. Kang G, Arora R, Chitambar SD, Deshpande J, Gupte MD, Kulkarni M, Naik TN, Mukherji D, Venkatasubramaniam S, Gentsch JR, Glass RI, Parashar UD. Indian Rotavirus Strain Surveillance Network. Multicenter, hospital-based surveillance of rotavirus disease and strains among indian children aged $<5$ years. J Infect Dis. 2009 Nov 1;200 Suppl 1:S147-53. doi: $10.1086 / 605031$.

7. World Health Organization. The Treatment of Diarrhea: A Manual for Physicians and Other Senior Health Workers, $4^{\text {th }}$ ed. Geneva: World Health Organization,2005(http://www.who.int/childadolescent) health/New_Publications/CHILD_HEALTH/ISBN_92 4_159318_0.pdf).

8. Bresee J, Parashar U, Holman R, Gentsch J, Glass R. Generic protocols for (i) hospitalbased surveillance to estimate the burden of rotavirus gastroenteritis in children and (ii) a communitybased survey on utilization of health care services for gastroenteritis in children. Document WHO/V \& B/02.15.Geneva: World Health Organization, 2002:167.

9. Nair GB, Ramamurthy T, Bhattacharya MK, Krishnan T, Ganguly S, Saha DR, et al. Emerging trends in the etiology of enteric pathogens as evidenced from an active surveillance of hospitalized diarrhoeal patients in Kolkata, India. Gut Pathog. 2010;2:4.

10. Centers for Disease Control and Prevention (CDC). Rotavirus surveillanceworldwide, 20012008. MMWR Morb Mortal Wkly Rep. 2008;57:12557.

11. Sachdev HP, Kumar S, Singh KK, Satyanarayana L, Puri RK. Risk factors for fatal diarrhea in hospitalized children in India. J Pediatr Gastroenterol Nutr. 1991; $12: 7681$

12. Phukan AC, Patgiri DK, Mahanta J. Rotavirus associated acute diarrhoea in hospitalized children in Dibrugarh, Norteast India. Indian J Pathol Microbiol. 2003;46:2748.

\section{How to cite this article?}

Sunil P, Thanda P, Mali D, Reddy R. Prevalence and outcome of rotaviral diarrhoea among children under five years- a single centre study. J PediatrRes. 2017;4(02):172-175.doi:10.17511/ijpr.2017.i02.14. 